\title{
Uniparental Isodisomy 6 Associated with Deficiency of the Fourth Component of Complement
}

Thomas R. Welch, ${ }^{\star}$ Linda S. Beischel," Edmund Choi, ${ }^{\ddagger}$ Kamala Balakrishnan, ${ }^{5}$ and Nancy A. Bishof Departments of ${ }^{*}$ Pediatrics, ${ }^{\ddagger}$ Microbiology and Molecular Genetics, and ${ }^{\S}$ Medicine, University of Cincinnati, and The Children's Hospital Research Foundation, Cincinnati, Ohio 45229-2899

\begin{abstract}
We identified an extremely rare condition, isolated complete deficiency of the fourth component of complement, in a child with systemic lupus erythematosus. The genes for $\mathrm{C} 4$ are located within the major histocompatibility complex (MHC) on the short arm of chromosome 6. The patient expressed only paternal phenotypes for proteins encoded by the MHC (HLA and GLO), yet was $46 \mathrm{XX}$ with no detectable 6p deletion.

Genomic DNA from patient, parents, and sibling was digested with restriction enzymes, and blots were probed for five chromosome 6 markers. At all loci, maternal and paternal RFLPs could be distinguished, and the patient showed only paternal bands. RFLP analysis of markers from four other chromosomes showed maternal and paternal contribution.

The data are consistent with uniparental isodisomy 6 (inheritance of two identical chromosome 6 haplotypes from the father and none from the mother). Direct analysis of genetic material from both parents, as well as detection of multiple protein polymorphisms encoded on chromosome 6, clearly demonstrates this novel mechanism for the expression of a recessive genetic condition. (J. Clin. Invest. 1990. 86:675678.) Key words: major histocompatibility complex • systemic lupus erythematosus $\bullet$ HLA $\bullet$ chromosome anomaly $\bullet$ molecular genetics
\end{abstract}

\section{Introduction}

Complete absence of the fourth component of human complement (C4) is an extraordinarily rare event, almost uniformly associated with the development of systemic lupus erythematosus (SLE) (1). The duplicated genes for C4 (C4A and C4B) are between the HLA-B and HLA-DR genes, within the major histocompatibility complex (MHC) on chromosome $6 \mathrm{p}$. Although deficiency of $\mathrm{C} 4 \mathrm{~A}$ or $\mathrm{C} 4 \mathrm{~B}$ alone is quite common, deficiency of both proteins on the same chromosome is extremely uncommon. Thus, most cases of complete C4 deficiency have been reported in products of consanguineous matings. Such individuals will be homozygous for the HLA

Address reprint requests to Dr. Welch, Children's Hospital Medical Center, Division of Nephrology, Elland \& Bethesda Avenues, Cincinnati, OH 45229-2899.

Received for publication 10 April 1990.

J. Clin. Invest.

(c) The American Society for Clinical Investigation, Inc.

0021-9738/90/08/0675/04 \$2.00

Volume 86, August 1990, 675-678 markers on the chromosome carrying the recessive $\mathrm{C} 4$ deficiency.

As the molecular organization of the MHC has become more understood, the mechanisms for C4 isotype deficiency have been defined. $\mathrm{C} 4 \mathrm{~A}$ deficiency most commonly is a result of a deletion involving the entire $\mathrm{C} 4 \mathrm{~A}$ gene and the adjacent 21-hydroxylase A pseudogene (2). C4B deficiency occurs either with a deletion of the $C 4 B$ gene (accompanied by a deleted 21-hydroxylase A or 21-hydroxylase B gene) or with a gene conversion event in which two $\mathrm{C} 4$ genes, both with $\mathrm{C} 4 \mathrm{~A}$ sequences, occur on the same chromosome (3). It is unusual to identify a $\mathrm{C4}$ gene of either isotype that is present but unexpressed. Very few cases of complete $\mathrm{C} 4$ deficiency have had complete genetic analysis. In a majority of those reported, the defect has been associated with a $\mathrm{C} 4 \mathrm{~B}$ gene deletion and a $\mathrm{C} 4 \mathrm{~A}$ gene that is unexpressed (4).

We have studied the mechanism of complete $\mathrm{C} 4$ deficiency in a 9-yr-old girl with SLE. Although she was homozygous for all HLA markers, it became obvious that her parents were not consanguineous. Detailed examination of several protein and DNA polymorphisms in the child and her family led to the recognition of a unique chromosomal anomaly, uniparental isodisomy of chromosome 6 .

\section{Methods}

Complement component measurements. Serum concentrations of $\mathrm{C} 4$ and 14 additional component and regulatory proteins of the complement system were measured by radial immunodiffusion using monospecific goat antisera prepared in this laboratory. $\mathrm{C} 4$ functional activity was measured in a standard hemolytic assay employing sensitized sheep erythrocytes (5).

Protein allotyping. Typing was performed for the products of nine loci in the MHC region. The class I proteins (HLA-A, C, B) and the class II proteins (HLA-DR, DQ) were typed by microlymphocytotoxicity of peripheral lymphocytes (6). The class III (complement) proteins (C4A, C4B, Bf) and the erythrocyte enzyme glyoxalase I were typed electrophoretically. For C4 typing, plasma was incubated with 8 $\mathrm{mU} / \mu \mathrm{l}$ of type VI neuraminidase (Sigma Chemical Co., St. Louis, MO), dialyzed overnight, and electrophoresed in agarose. The gel was immunofixed with anti-human $\mathrm{C} 4$, and allotypes were assigned according to standard nomenclature $(7,8)$. For Bf typing, plasma was subjected to agarose electrophoresis and immunofixation with antihuman Bf (9). For glyoxalase I (GLO) typing, erythrocyte lysates were subjected to electrophoresis on cellulose acetate membranes, with enzyme detection by a functional overlay (10).

Restriction enzyme digestion of genomic DNA and Southern analysis. DNA was isolated from peripheral mononuclear cells by phenol and chloroform extraction (1.1). The DNA was digested with Taq I, Kpn I, Eco RI, Bgl II, Nla IV, Hind III, Bam HI, Xba I, and Rsa I, according to the supplier's instructions. The digested DNA was elec- 
trophoresed in agarose, transferred to nylon membranes and hybridized with ${ }^{32} \mathrm{P}$-labeled probes, prior to autoradiography. The $\mathrm{C} 4$ probe used was a 500-bp fragment of the $5^{\prime}$ end of the $\mathrm{C} 4 \mathrm{cDNA}$, produced by Bam HI/Kpn I digest of pAT-A (12). The 21-hydroxylase (21-OH) probe was a $900 \mathrm{bp}$ fragment, produced by a $\mathrm{Bgl}$ I digest of the genomic insert in p21-K4 (2). Full-length cDNA probes were used for DRB and DQB (13). In addition, a series of informative non-MHC probe/enzyme combinations were employed in studying the family; these Southern analyses were performed by Collaborative Research, Inc. (Boston, MA) (14).

Karyotyping. Cytogenetic analysis of metaphase-banded chromosomes from the patient's peripheral leukocytes was performed by the clinical cytogenetics laboratory of Children's Hospital Medical Center, using standard techniques.

\section{Results}

Patient. MM is a 9-yr-old girl who was initially evaluated because of malar erythema, vasculitic skin lesions, and photosensitivity. The child's serum contained anti-nuclear antibodies, as well as anti-Sm and anti-Ro (SS-A). Her serum was consistently negative, however, for antibodies to doublestranded DNA. Her cutaneous lesions have responded well to

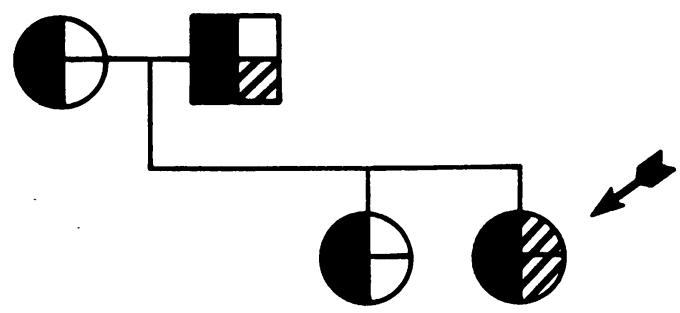

\section{a) SERUM C4

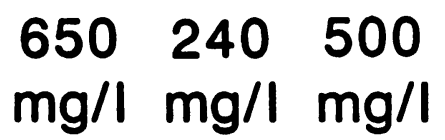

b) C4 PROTEIN

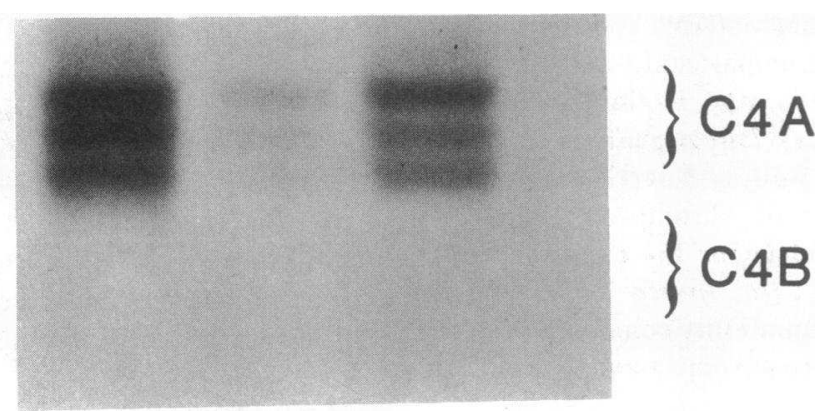

\section{c) GLO PROTEIN}

\section{d) $\mathrm{MHC}$ HAPLOTYPES}
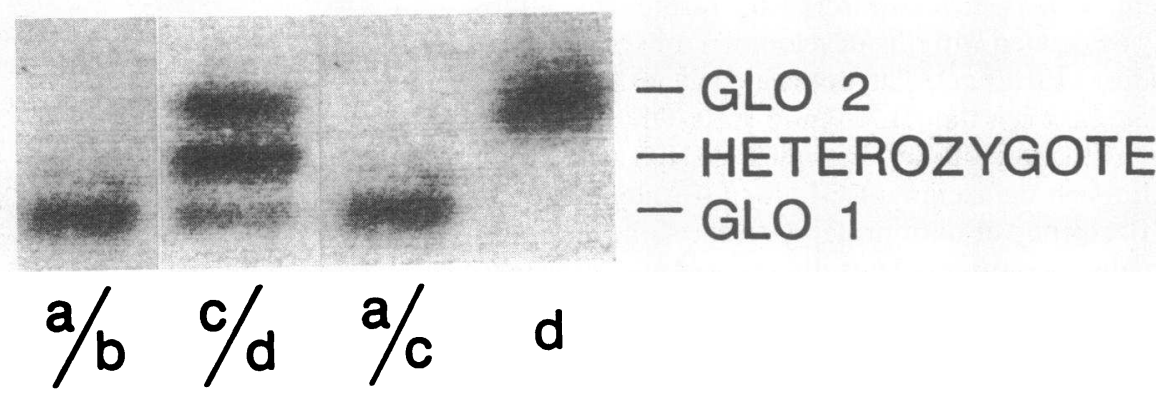

Figure 1. Family pedigree with proband (MM) indicated by an arrow. Protein allotypes are shown for the MHC region of chromosome 6 . ( $a$ ) $\mathrm{C} 4$ serum concentrations in family members, with values expressed as milligrams per liter (normal ranges from 210-750). No C4 was detectable in the proband. (b) $\mathrm{C} 4$ allotypes after immunofixation electrophoresis. All family members lacked C4B protein (indicated in the pedigree by black shading of symbols), the father is heterozygous for C4A deficiency as well (stippled shading), and the proband expresses no C4 protein. (c) Glyoxalase allotyping, showing the absence of the maternal allotype (GLO1) in the proband. (d) MHC haplotypes assigned to family members. "QO" is the designation for an unexpressed C4 gene. Allotypes in the proband were consistent with inheritance of a single (paternal) haplotype. Haplotype a: HLA-A2, -Cw5, -B44, BfS, C4A3, C4BQO, -DR4, -DRw53, -DQw7, GLO1; haplotype b: HLA-A3, -Cw4, -B35, BfF, C4A3,2, C4BQO, -DR1, -DRw53, -DQw1, GLO1; haplotype $c$ : HLA-A30, -Cw6, -B13, BfF, C4A3, C4BQO, -DR6, -DRw52, -DQw1, GLO1; haplotype $d$ : HLA-A28, -Cw3, -B40, BAS, C4AQO, C4BQO, -DR6, -DRw52, -DQw1, GLO2. 
treatment with hydroxychloroquine. Her mother, father, and sister are all healthy and were available for study.

Serum complement components. Radial immunodiffusion on three separate serum samples detected no $\mathrm{C} 4$ protein in MM. She consistently had normal serum concentrations of $\mathrm{Cl}$ through $\mathrm{C} 3, \mathrm{C} 5$ through $\mathrm{C} 9, \mathrm{Bf}, \mathrm{H}, \mathrm{I}, \mathrm{C} 4$ binding protein, properdin, and $\mathrm{Cl}$ inhibitor. The patient's serum had no $\mathrm{C4}$ function $(<0.03 \%$ of a normal serum pool by a sensitive hemolytic assay). Serum C4 concentrations in the other family members are shown in Fig. 1.

HLA and class III typing. HLA typing (Fig. 1) showed that MM inherited only a single paternal HLA haplotype $(d)$. No family member expressed C4B protein. The father, in addition, appeared heterozygous for $\mathrm{C} 4 \mathrm{~A}$ deficiency, by pedigree and by serum $\mathrm{C} 4$ concentration. Bf typing was not informative in the family. Glyoxalase allotyping was consistent with the lack of maternal $6 \mathrm{p}$-derived proteins, since $\mathrm{MM}$ is homozygous for the glyoxalase-2 allotype, while her mother is homozygous for the 1 allotype. Thus, the patient demonstrated no maternal contribution from HLA-A to glyoxalase, a region of chromosome 6 containing at least $5,000 \mathrm{~kb}$ of DNA. Normal inheritance of both maternal haplotypes $a$ and $b$ (Fig. 1) was demonstrated in eight additional family members (data not shown).

Southern analysis of chromosome 6 DNA. Representative blots (Fig. 2) demonstrate the absence of maternally derived chromosome 6 DNA sequences in the patient by any probe/ enzyme combination. Restriction fragment analysis showed
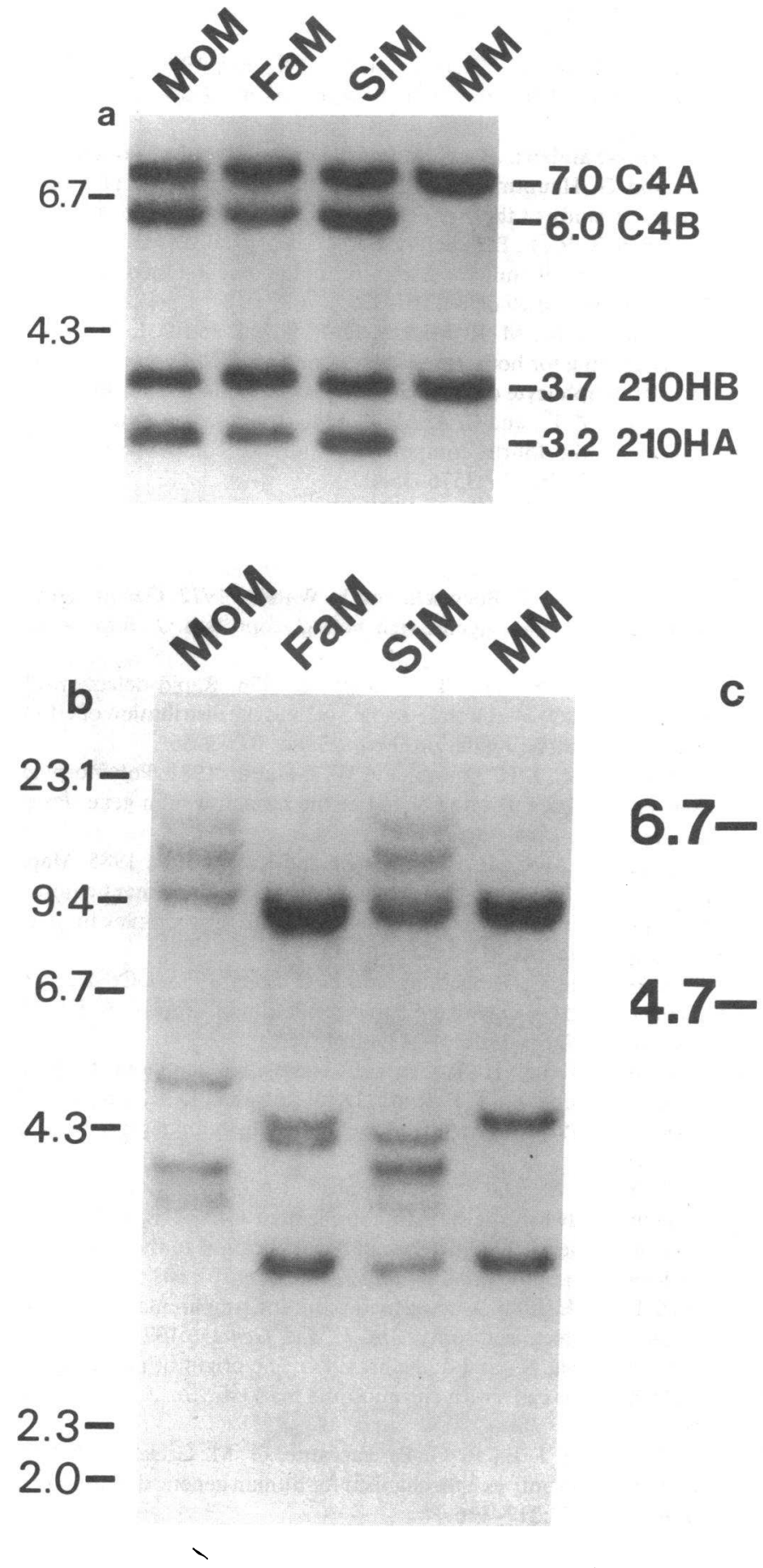
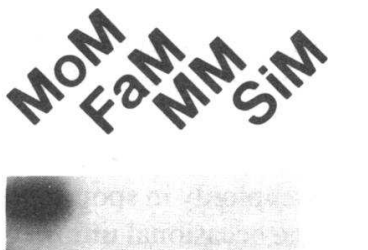

Figure 2. Analysis of DNA restriction fragment length variants, demonstrates absence of maternally derived fragments in the proband for loci on both arms of chromosome 6. The proband (MM) appears homozygous for paternally derived variants. MoM, mother; FaM, father, SiM, sibling. Migration of molecular size markers is indicated (in $\mathrm{kb})$ at the left of each photograph. (a) Taq I digest hybridized simultaneously with probes for $\mathrm{C} 4$ and $21-\mathrm{OH}$. The proband is homozygous for a deletion involving C4B and 21-OHA (absence of 6- and 3.2-kb fragments), while the mother and sibling do not have such a deletion. Densitometric analysis of fragments confirms that the father is heterozygous for this deletion. (b) Eco RI digest hybridized with a cDNA probe for DRB. No unique maternally derived bands are present in the proband. (c) Rsa I digest hybridized with a probe (CRI-L1065) for the telomeric end of chromosome 6q. This autoradiograph was provided by Collaborative Research, Inc. The proband displays no maternally derived sequences. 
that haplotype $d$ (Fig. 1), the only one present in the patient, contained C4B and 21-OHA gene deletions and an unexpressed C4A gene. The absence of a $\mathrm{C} 4 \mathrm{~B}$ deletion in the mother and sibling, while protein phenotyping (Fig. 1) shows no $\mathrm{C} 4 \mathrm{~B}$ protein, is explained by a gene conversion in which C4B locus products contain C4A specific sequences (15). DNA polymorphisms at the DR (Fig. 2) and DQ (not shown) loci allow the 2 paternal haplotypes (Fig. 1, $c$ and $d$ ) to be distinguished even though both are DR6, DQW1.

Hybridization of a telomeric 6q probe (CRI-L1065) (14) with RSA I-digested DNA generated an informative RFLP (Fig. 2). This confirmed that the patient lacked a maternally derived fragment from the long arm of chromosome 6 as well.

Southern analysis-non-chromosome 6. The family's DNA was next hybridized with probes specific to four additional chromosomes (1: CRI-L336, Pst I; 3: CRI-L892, Taq I; 5: CRI-L45, Msp I; 7: CRI-5194, Pst I) (14). All of these analyses were consistent with the reported family relationship and showed normal inheritance of maternal fragments (not shown).

Karyotyping. Cytogenetic analysis of metaphase-banded chromosomes from the patient's peripheral leukocytes demonstrated a normal 46XX karyotype with no visible deletion or other abnormality of $6 \mathrm{p}$.

\section{Discussion}

This child, with complete C4 deficiency and a 46XX karyotype, had no evidence of maternal DNA on either arm of the 6th chromosome. In addition, she expressed a single paternal haplotype at all loci examined on this chromosome, with hybridization intensity consistent with two copies of these paternal genes. The mechanism by which these findings can be explained is the presence of two identical paternal chromosome 6's without a maternal chromosome (uniparental isodisomy).

The concept of uniparental isodisomy was introduced in 1980 (16). Reviewing the incidence of aneuploidy in spontaneous abortuses, Engel hypothesized that the occasional union of a disomic gamete with a gamete nullisomic for its homologue could result in a euploid product with an extensive series of homozygous alleles. In theory, this could result in the expression of recessive traits in a child despite only a single carrier parent. Uniparental disomy has been demonstrated in some diploid cell lines derived from parents with mosaic Down's syndrome (17).

Uniparental (maternal) disomy for chromosome 7 was suggested recently in a child with cystic fibrosis (18). Unfortunately, this child's mother was deceased and, thus, the mother's haplotypes could only be inferred from analysis of relatives. In our case, the availability of both parents and a sibling, as well as the fortuitous presence of informative differences in protein phenotypes and polymorphisms of DNA at several loci, provide unequivocal evidence for the existence of this novel mechanism for the expression of recessive genetic traits. It also demonstrates that, in the absence of complete family studies, homozygosity of HLA markers need not always imply consanguinity. In order to recognize uniparental isodisomy, two conditions must be met. First, the involved chromosome must carry a recessive trait whose phenotype is a recognizable condition which will bring the individual to attention. Secondly, the trait must be linked to a known informative protein or DNA polymorphism. Thus, it is likely that the prevalence of this chromosomal anomaly will be underestimated.

\section{Acknowledgments}

Richard Erbe (Collaborative Research, Inc.) performed the non-MHC Southern analyses and provided helpful discussion. We thank Joseph Levinson and Christos Gabriel for patient referral, Shirley Soukup for the cytogenetic analysis, Michael Carroll and Eric Long for the probes, and Barbara Pieper for secretarial assistance.

\section{References}

1. Agnello, V. 1986. Lupus diseases associated with hereditary and acquired deficiencies of complement. Springer Semin. Immunopathol. 9:161-178.

2. Schneider, P. M., M. C. Carroll, C. A. Alper, C. Rittner, A. S. Whitehead, E. J. Yunis, and H. R. Colten. 1986. Polymorphism of the human complement $\mathrm{C} 4$ and steroid 21-hydroxylase genes. J. Clin. Invest. 78:650-657.

3. Welch, T. R., L. S. Beischel, and E. M. Choi. 1989. Molecular genetics of C4B deficiency in IgA nephropathy. Hum. Immunol. 26:353-363.

4. Uring-Lambert, B., F. Mascart-Lemone, M.-M. Tongio, J. Goetz, and G. Hauptmann. 1989. Molecular basis of complete C4 deficiency. A study of three patients. Hum. Immunol. 24:125-132.

5. Welch, T. R., L. Beischel, A. Berry, J. Forristal, and C. D. West. 1985. The effect of null C4 alleles on complement function. Clin. Immunol. Immunopathol. 34:316-325.

6. Mittal, K. K., M. R. Mickey, D. P. Singal, and P. I. Terasaki. 1968. Serotyping for homotransplantation. XVIII. Refinement of microdroplet lymphocyte cytotoxicity test. Transplantation. 6:913-927.

7. Awdeh, Z. L., and C. A. Alper. 1980. Inherited structural polymorphism of the fourth component of human complement. Proc. Natl. Acad. Sci. USA. 77:3576-3580.

8. Sim, E., and S. J. Cross. 1986. Phenotyping of human complement component C4, a class-III HLA antigen. Biochem. J. 239:763767.

9. Alper, C. A., T. Boenisch, and L. Watson. 1972. Genetic polymorphism in human glycine-rich beta-glycoprotein. J. Exp. Med. 135:68-80.

10. Khan, P. M., and B. A. Doppert. 1976. Rapid detection of glyoxalase I (GLO) on cellulose acetate gel and the distribution of GLO variants in a Dutch population. Hum. Genet. 34:53-56.

11. Bell, G. I., J. H. Karam, and W. J. Rutter. 1981. Polymorphic DNA region adjacent to the $5^{\prime}$ end of the human insulin gene. Proc. Natl. Acad. Sci. USA. 78:5759.

12. Carroll, M. C., R. D. Campbell, and R. R. Porter. 1985. Mapping of steroid 21-hydroxylase genes adjacent to complement component C4 genes in HLA, the major histocompatibility complex in man. Proc. Natl. Acad. Sci. USA. 82:521-525.

13. Tonnelle, C., R. DeMars, and E. O. Long. 1985. DO $\beta$ : a new $\beta$ chain gene in HLA-D with a distinct regulation of expression. $E M B O$ (Eur. Mol. Biol. Organ.) J. 4:2839-2847.

14. Donis-Keller, H., P. Green, C. Helms, S. Cartinhour, B. Weiffenbach, K. Stephens, T. P. Keith, D. W. Bowden, D. R. Smith, E. S. Lander, et al. 1987. A genetic linkage map of the human genome. Cell. 51:319-337.

15. Yu, C. Y., and R. D. Campbell. 1987. Definitive RFLP's to distinguish between the human complement C4A/C4B isotypes and the major Rogers/Chido determinants: application to the study of $\mathrm{C4}$ null alleles. Immunogenetics. 25:383-390.

16. Engel, E. 1980. A new genetic concept: uniparental disomy and its potential effect, isodisomy. Am. J. Med. Genet. 6:137-143.

17. Niikawa, N., and T. Kajii. 1984. The origin of mosaic Down Syndrome: four cases with chromosome markers. Am. J. Hum. Genet. 36:123-130.

18. Spence, J. E., R. G. Perciaccante, G. M. Greig, et al. 1988. Uniparental disomy as a mechanism for human genetic disease. Am.J. Hum. Genet. 42:217-226. 